\title{
International Journal of Engineering Research and Development
}

e-ISSN: 2278-067X, p-ISSN : 2278-800X, www.ijerd.com

Volume 4, Issue 11 (November 2012), PP. 51-54

\section{Automated Irrigation System}

\author{
H.T.Ingale ${ }^{1}$, N.N.Kasat ${ }^{2}$ \\ ${ }^{1}$ GF's G.C.O.E, Jalgaon, Assistant Professor \\ ${ }^{2}$ SIPNA's C.O.E.T, Amaravati Associate Professor
}

\begin{abstract}
Irrigation is the key to a successful garden. Long gone are the days of manual watering or relying on a friend to water when you are on vacation or away on business. It's very important that every farmer must possess the perfect knowledge about growing specifications of plants in case of water supply. In Indian economy seventy percent part is depend on agriculture and under this condition if there will be any system which will help to provide precise level of water to plants then it will definitely leads to beneficial for our economy. So to help them we are making an attempt by introducing our project "Micro controller based drip irrigation system". By using sensors we will make them aware about changing conditions of humidity level according to weather so according to changing conditions of humidity they will be able to schedule the proper timing for water supply.
\end{abstract}

Keywords:-Irrigation, Microcontroller, Sensor, Humidity.

\section{INTRODUCTION}

Water saving is the main aim of our work. Very small amount of water is useful for all living organisms and it's the human being who is mainly responsible for wastage of water. There are many sources by which human makes the water hazardous for other living organisms plus there are many ways by which human being is responsible for wastage of water. One major reason of which is unnecessary wastage of water in agriculture field due to unawareness of farmers about sufficient supply of water[3]. There are many plants that are very sensitive to water levels and they required specific level of water supply for proper growth, if this not they may die or results in improper growth. It's hardly possible that every farmer must possess the perfect knowledge about growing specifications of plants in case of water supply. In Indian economy seventy percent part is depend on agriculture and under this condition if there will be any system which will help to provide precise level of water to plants then it will definitely leads to beneficial for our economy. So to help them we are making an attempt by introducing our project "Automated Irrigation System". By using sensors in our work we will make them aware about changing conditions of humidity level according to weather so according to changing conditions of humidity they will be able to schedule the proper timing for water supply.

\section{IRRIGATION SYSTEM}

In the field of agriculture, use of proper method of irrigation is very important from yield point of view and scarcity of water. Traditional drip irrigation is a method of applying water and fertilizer near the root zone of the crop to minimize low humidity stress within the root zone in the soil. However, being a manual system that works under low or medium pressure, unmeasured quantity of water is given to the crop. Sometimes excessive amount of water is continuously given to the crop or sometimes very less amount of water is given to the crop, defeating the purpose of the system [2]. In this, Low humidity stress has significant effect on the plant growth, crop response, and timing of maturity, quality and yield of product. This system makes use of Humidity sensor, Temperature sensor are used. $\mathrm{O} / \mathrm{p}$ of these sensors is given to the A/D converter, which converts it into digital domain and then fed to the controller for the further process. The software of the system consists of data acquisition, calibration, displaying information and taking decision. The developed system has numerous advantages such as automation, user-friendly measurement and upgrading of the design is possible. Moreover the system is portable, field usable, reprogrammable, and can be used at any geographic positions and weather conditions. In the conventional drip system, quantity of water applied to the plants depends on various parameters such as type of soil, rate of evaporation, type of crop and atmospheric conditions etc. Using some standards based on day to day experience, water requirement of crop per day is calculated. Water required for the crop is supplied by keeping motor ON for a particular period. Thus farmer has to follow the irrigation timetable meticulously and some supervisor needs to be present there for whole day, it is always the possibility that more water may be given to the crop or in some cases lesser amount of water may be given, which may affect the yield [1].

\section{A. $\quad$ Introduction to Controller}

Micro controller IC $89 \mathrm{c} 52$ is heart of our work. This micro controller IC having number of advantages:

1) Internal $64 \mathrm{~K}$ bytes of electrically erasable programmable read only memory for feeding program so that there is no need of external EPROM.

2) Four 8 bit i/p o/p port out of which we use one port to read ADC o/p other port is use to connect relay and display for operating devices

3) Operating voltage of 3.5 to 6 v D.C. This is easily available by using voltage regulator IC.

4) Internal 128 byte RAM to store temporally storage of data. In which we can feed took up table to turn ON/OFF relay.

5) Two 16 bit time/counter are present for timing and counting purpose. 
6) 4 external and 2 internal interrupt are available.

Micro controller can read the data available at o/p of A/D converter and store in memory and compare with the set point to turn ON or OFF relay If comparison is equal then operate relay. $12 \mathrm{MHz}$ quartz ceramic crystal is connected between pin XTAL and XTAL of micro controller to produce machine cycle for fetch and execution of instruction. And at pin 9 RST pin we connect R.C n/w to provide reset pulse when power is turn on so those program executions start from memory location $0000 \mathrm{H}[5]$.

\section{B. Implementation of Controller}

The main aim of this work is to save the water, electricity and improve the growth of plant. Considering farmer's economical conditions we have prepared a circuit which is cheap and reliable. We have used 89C52 microcontroller for low consumption, low cost, small circuit size and easy to implement. Micro controller can read the data available at o/p of A/D converter and store in memory and compare with the set point to turn ON or OFF relay If comparison is equal then operate relay [6]. $12 \mathrm{MHz}$ quartz ceramic crystal is connected between pin XTAL and XTAL of micro controller to produce machine cycle for fetch and execution of instruction. And at pin 9 RST pin we connect R.C n/w to provide reset pulse when power is turn on so that program execution starts from memory location $0000 \mathrm{H}$. For our all IC we require 5 v D.C., $+12 \mathrm{vdc}$,$12 \mathrm{v}$ dc supply which can be generated by step down transformer, full wave bridge rectifier, filter condenser and voltage regulator IC.

The operating relay makes the motor ONN or OFF according to humidity \& temperature sensor by using the program. In this way we can convert physical quantity (i.e. temp, humidity) in to digital equivalent. Micro controller IC 89 c52 serve two task first generate control signal at port P2 for A to D converter \& read equivalent digital data at (D0 to D7) at port P1 (P2.0 to P2.7). Thus digital data are temporally storage in internal register of micro controller IC2. This Hex code is transmitted in IC HT12E, Serial encoding data transmission. According to this Hex code digital data is transmitted through R.F. transmitter.

At receiver section RF receiver operated at same frequency and micro controller ic 89c52.The transmitted data is receive at receiver end and shown on LCD display In our project we use 16x2 LCD display to show status of devices In recent years the LCD is finding widespread use replacing LEDs (seven segment LEDs or other multi-segment LEDs). We check the calibrated value. If it is greater than UTP value, then the motor relays becomes OFF. When it is less than LTP value, the motor relay becomes ON. The basic concept of project is to keep humidity \& temperature level up to certain level for growth of crop.

\section{Hardware interface}
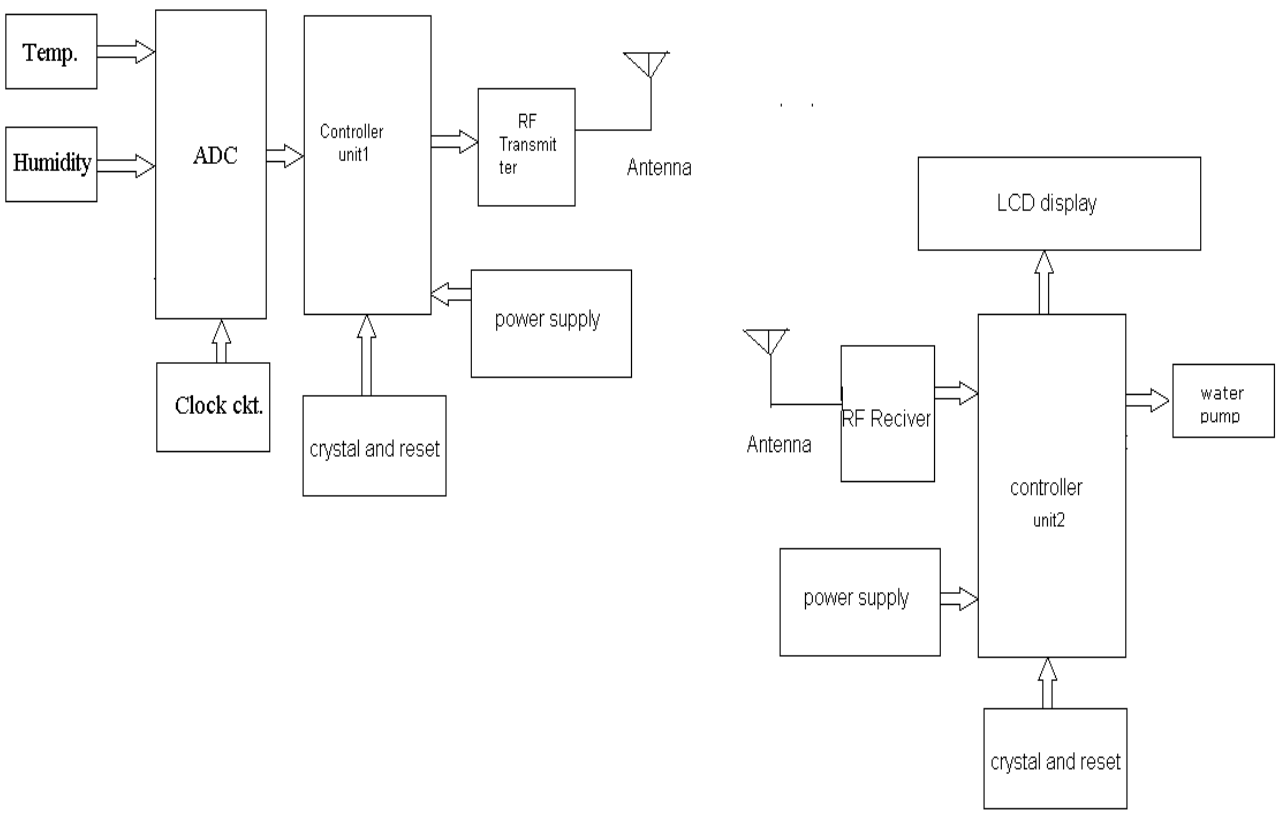

D. Proposed Dataflow chart 


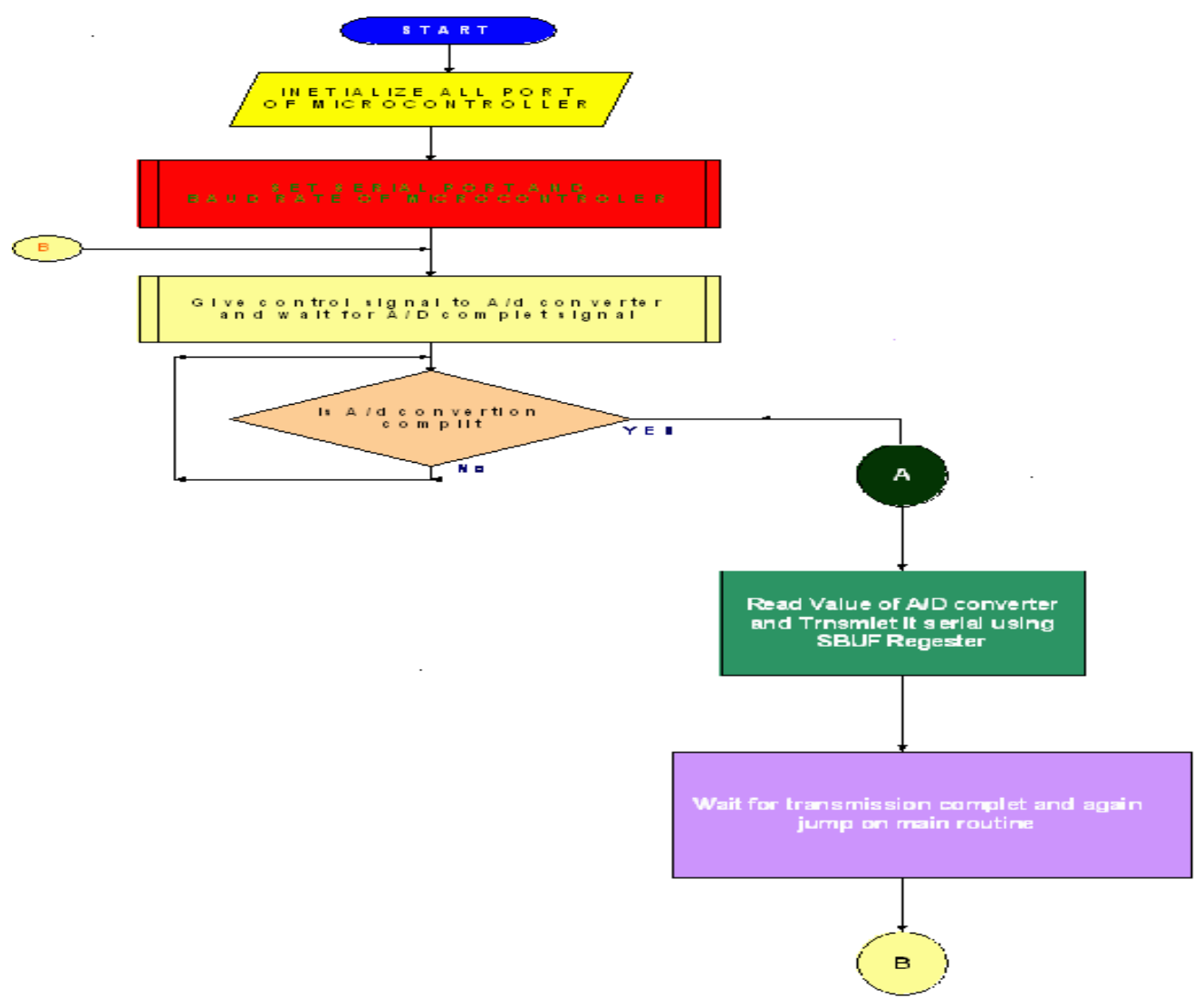

FLOWEHART FOR RECIVER SECTION

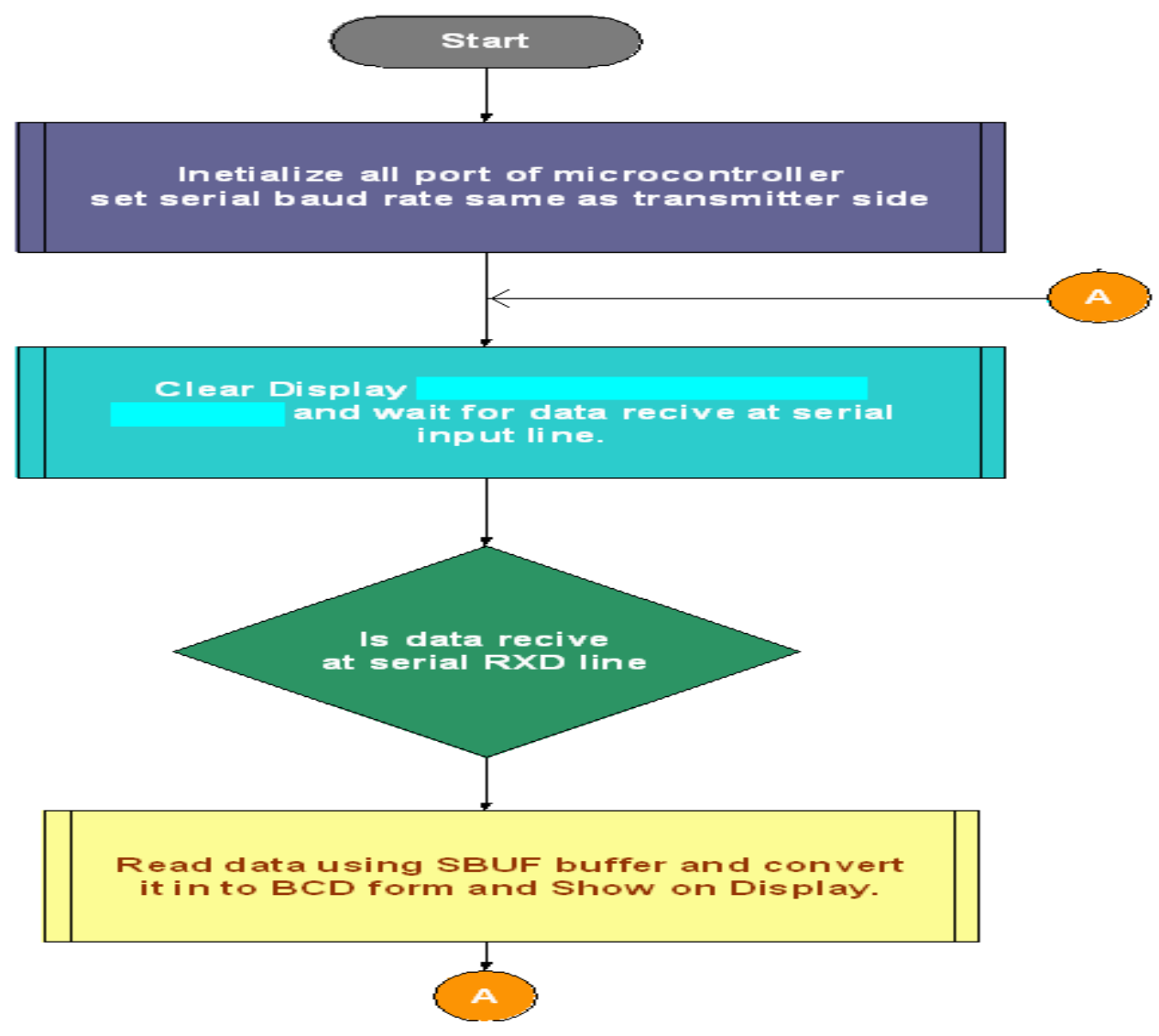




\section{CONCLUSION}

The system provides with several benefits and can operate with less manpower. The system supplies water only when the humidity in the soil goes below the reference. Due to the direct transfer of water to the roots water conservation takes place and also helps to maintain the moisture to soil ratio at the root zone constant to some extend. Thus the system is efficient and compatible to the changing environment. Also the system saves the water and improves the growth of plants.

\section{REFERENCES}

[1]. Gonzalez, R.A., Struve, D.K. and L.C. Brown. 1992. A computer-controlled drip irrigation system for container plant production. HortTechnology.2 (3):402-407.

[2]. Fangmeier, D.D., Garrot, D.J., Mancino,C.F. and S.H. Husman. 1990. Automated Irrigation Systems Using Plant and Soil Sensors. In: Visions of the Future. ASAE Publication 04-90. American Society of Agricultural Engineers, St. Joseph, Michigan, pp. 533-537.

[3]. Ayars, J.E., Phene, C.J., Hutmacher, R.B., Davis, K.R., Schoneman, R.A., Vail,S.S. and Mead, R.M. (1999). Subsurface drip irrigation of row crops: a review of 15 years research at the Water Management Research Laboratory. Agricultural Water Management 42: 1-27.

[4]. Yan Xijun, Lu limei, Xu Lizhong, "The Application of wireless sensor network in the Irrigation Area Automatic System", International Conference on Networks Security, Wireless Communications and Trusted Computing 2009, pp. 21-24.

[5]. Daniel K. Fisher and Hirut Kebede "A low-cost microcontroller-based system to monitor crop temperature and water status", Computers and Electronics in Agriculture, Elsevier B.V., pp. 168-173, 2010.

[6]. Abhinav Rajpal, Sumit Jain, Nistha Khare and Anil Kumar Shukla, "Microcontroller based Automatic Irrigation System with Moisture Sensors", Proceedings of the International Conference on Science and Engineering, 2011, pp. 94-96.

[7]. Rajeev G Vishwakarma, "Wireless Solution for Irrigation in Agriculture", Proceedings of the International Conference on Signal Processing, Communication, Computing and Networking Technologies, pp. 61-63, 2011.

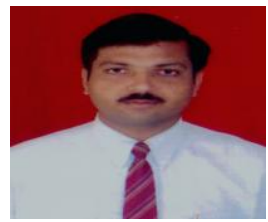

H.T.Ingale is presently Assistant Professor in Electronics \& Communication Engg. Department Godavari College of Engg., affiliated to North Maharashtra University- Jalgaon, Maharashtra, India.. His research interests include Signal Processing \& Image Processing., Neural network.

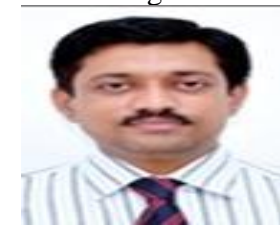

N.N.Kasat is presently Associate Professor in Electronics \& Communication Engg. Department Sipana College of Engg. \& Technology, affiliated to Sant Gadgebaba Amaravati University- Amaravati, Maharashtra, India.. He received the M.E degree from the SGBAU Amaravati and presently he is persuing PhD degree from SGBAU Amaravati. His research interests include Microprocessors, Microcontrollers \& Embedded systems., Neural network. 